\title{
Learning from tuberculosis: COVID-19 highlights the need for more robust infection control policy
}

\author{
Alexander Moran ${ }^{1}$, Matsie Mphahlele ${ }^{2}$, Lindiwe Mvusi ${ }^{3}$, Cindy Dlamini ${ }^{4}$, Sevim \\ Ahmedov $^{5}$, Hala Jassim AlMossawi ${ }^{1}$, Neeraj Kak ${ }^{1}$
}

\footnotetext{
${ }^{1}$ University Research Co., LLC (URC), Center for Innovation and Technology, Chevy Chase, Maryland, USA

${ }^{2}$ University Research Co., LLC (URC), USAID Tuberculosis South Africa Project, Pretoria, Gauteng, South Africa

${ }^{3}$ National Department of Health, Pretoria, Gauteng, South Africa

${ }^{4}$ United States Agency for International Development (USAID), Pretoria, Gauteng, South Africa

${ }^{5}$ United States Agency for International Development (USAID), Washington, D. C., USA
}

The COVID-19 pandemic highlights the need for supporting airborne infection prevention and control programs to improve preparedness for future public health threats.

\begin{abstract}
C
\end{abstract} oronavirus disease 2019 (COVID-19) represents an unprecedented challenge in modern public health practice. Having spread to over 180 countries and having affected millions of individuals, ailability of other essential medical services [1]. This rapidly-moving pandemic has laid bare the importance of effective surveillance, quarantine, testing and diagnosis, contact tracing and hospital infection prevention and control measures. Certain countries, including Singapore, have effectively contained community spread of the virus through early and broad quarantine, testing and contact tracing measures [24]. In countries like Italy and Spain - where responses were slower, narrower in focus and less consistently implemented - COVID-19 transmission has spread widely in the community, and responses have shifted from containment to mitigation [4,5]. In these countries where containment measures have failed, health systems must plan to ration life-saving medical equipment like mechanical ventilators [6-8]. As COVID-19 spreads to more countries daily, governments begin to prepare for community spread and start to impose travel restrictions, quarantines and physical distancing measures in an effort to "flatten the curve" and to minimize health system strain $[9,10]$.

Minimizing nosocomial (hospital-based) infections is integral to an effective COVID-19 response. The World Health Organization (WHO) has published interim COVID-19 infection prevention and control (IPC) guidance, which focuses on administrative controls (including policy, guidance, training and triage practices), environmental controls (including ventilation and waste management) and personal protective equipment (PPE, including rational use thereof) [11]. As more patients become sicker and require hospitalization, public health leaders must look toward existing hospital-based IPC programs to ensure a broad, consistent prevention and control effort. Tuberculosis (TB) IPC programs are uniquely prepared for this challenge and can be leveraged to mobilize already-trained health care workers, to adapt existing TB IPC guidance documents and to implement existing administrative controls, environmental controls and PPE practices. 
In the midst of an unprecedented public health emergency, we must adapt and strengthen existing infection prevention and control programs to reduce the spread of COVID-19 while preventing a resurgence of other infectious diseases like tuberculosis.
Aside from responding to this global emergency, countries must also prepare for future outbreaks and continue to support and strengthen existing infectious disease programs [12]. In this viewpoint, we discuss the readiness of World Health Organization (WHO) Africa Region countries for COVID-19 IPC implementation, offer an example of a successful TB IPC intervention in South Africa, and describe how this intervention can be adapted for the COVID-19 response. We also discuss the need for continued momentum and sustainability for IPC programs before, during and after a pandemic threat.

\section{COVID-19 INFECTION PREVENTION AND CONTROL READINESS}

WHO recently published interim IPC guidance for COVID-19 describes standard airborne IPC practices for hospital settings, which mirror the general WHO minimum requirements for IPC programs $[11,13]$. The interim guidance includes the following components, with example interventions described within each component:

\section{Triage and administrative controls}

- Establish a well-equipped triage station at the entrance of health facilities which is supported by trained staff

- Use screening questionnaires according to the most updated case definition

- Post signs in public areas asking symptomatic patients to alert health care workers (HCWs)

- Ensure social distancing (ie, a minimum of $1 \mathrm{~m}$ between people) or screening people as they enter

- Ensure that patients cover their nose and mouth with a tissue or elbow, scarf or home-made mask

- Offer a medical mask to patients with suspected COVID-19 in waiting rooms or in cohorting areas

- Encourage good hand hygiene with handwashing with soap and water or alcohol gel

- Provide adequate training to HCWs with weekly in-service training

- Establish a surveillance process for possible COVID-19 infection among HCWs

- Monitor HCW compliance with standard IPC precautions

- Restrict visiting hours to facilities as well as the number of people that can visit health facilities

- Ensure posters, patient education and handwashing/sanitizing.

\section{Environmental and engineering controls}

- Ensure adequate ventilation in rooms where aerosol-generating procedures are performed

- Limit room capacity to the absolute minimum for patient care and support

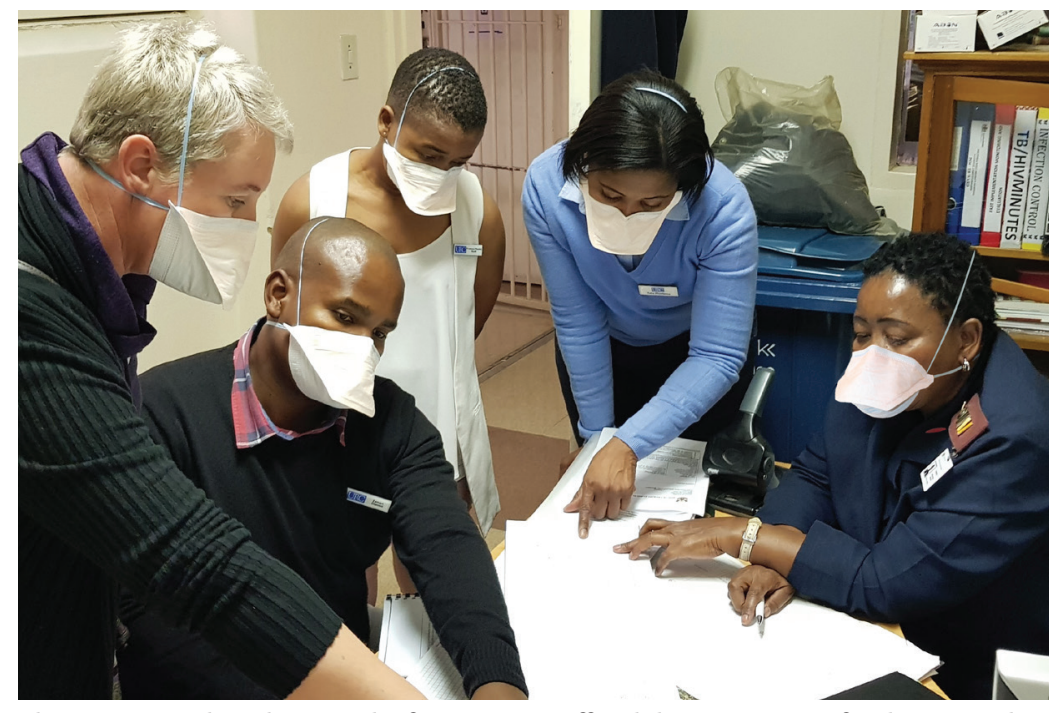

Photo: USAID Tuberculosis South Africa Project staff and the area manager for the TB Ward at Pretoria West Hospital conduct a chart audit as part of the FAST intervention (from the collection of University Research Co., LLC., used with permission).
Personal Protective Equipment

- Implement standard PPE precautions

- Implement additional contact and droplet precautions before entering the room of a patient with suspected or confirmed COVID-19

- Use particulate respirators (at least as protective as N95 or FFP2).

In the context of these interim guidelines, WHO published a dashboard summarizing the readiness of countries in the WHO African Region for COVID-19 response [14]. These questions aim to describe IPC readiness and are presented in Table 1. We have separated the questions into the three IPC domains: administrative, environmental and PPE. Most questions $(n=7)$ reflected readiness for implementing administrative con- 
Table 1. WHO African Region Readiness Response Sheets for infection prevention and control, with yes/no responses overall and for South Africa

\begin{tabular}{|c|c|c|c|c|c|c|}
\hline \multirow[b]{2}{*}{ Question } & \multirow[b]{2}{*}{ IPC domain } & \multirow[b]{2}{*}{ Responses } & \multicolumn{3}{|c|}{ Country responses } & \multirow{2}{*}{$\begin{array}{l}\text { SOUTH AFRicA } \\
\text { RESPONSE }\end{array}$} \\
\hline & & & Yes & No & $\%$ Yes & \\
\hline $\begin{array}{l}\text { Is there an IPC team responsible to follow up on exposed } \\
\text { HCWs? What policies are in place for confirmed cases of HCWs } \\
\text { in contact with patients? }\end{array}$ & Administrative & 47 & 24 & 23 & $51 \%$ & Yes \\
\hline $\begin{array}{l}\text { Is there a triaging system that can be applied to ARI in the } \\
\text { health facilities? }\end{array}$ & Administrative & 48 & 26 & 22 & $54 \%$ & No \\
\hline $\begin{array}{l}\text { Are health workers trained on IPC measures for respiratory } \\
\text { infections? }\end{array}$ & Administrative & 48 & 28 & 20 & $58 \%$ & Yes \\
\hline $\begin{array}{l}\text { Are standard precautions applied for all patients with suspected } \\
\text { or confirmed high-threat pathogens? }\end{array}$ & Administrative & 48 & 28 & 20 & $58 \%$ & Yes \\
\hline $\begin{array}{l}\text { Are there general IPC guidelines in place at both facility and } \\
\text { community levels? }\end{array}$ & Administrative & 48 & 28 & 20 & $58 \%$ & Yes \\
\hline $\begin{array}{l}\text { Does the HCFs/Health Districts have existing IPC committees or } \\
\text { structures? }\end{array}$ & Administrative & 48 & 29 & 19 & $60 \%$ & Yes \\
\hline Is there a functioning national IPC program in place in country? & Administrative & 48 & 33 & 15 & $69 \%$ & Yes \\
\hline $\begin{array}{l}\text { Is there a system in place for collection and disposal of contami- } \\
\text { nated medical waste? }\end{array}$ & Environmental & 48 & 37 & 11 & $77 \%$ & Yes \\
\hline $\begin{array}{l}\text { Is PPE available for medical staff for screening? If so what PPE is } \\
\text { available and how many and in what quantities? }\end{array}$ & PPE & 44 & 29 & 15 & $66 \%$ & Yes \\
\hline $\begin{array}{l}\text { Is PPE available for medical staff for case management? If so } \\
\text { what PPE is available and how many and in what quantities (are } \\
\text { there PAPRS, N95s, Surgical masks, gowns, gloves, etc.)? }\end{array}$ & PPE & 48 & 33 & 15 & $69 \%$ & Yes \\
\hline
\end{tabular}

IPC - infection prevention and control, PPE - personal protective equipment, HCW - health care worker

trols, and the remaining three questions describe readiness to implement PPE $(n=2)$ and environmental controls $(n=1)$. Countries were overall least prepared for administrative control implementation, with an average $58 \%$ of countries $(n=48)$ responding "yes" to administrative control readiness questions. Within administrative controls, countries were overall least prepared for the following questions: "Is there an IPC team responsible to follow up on exposed HCWs? What policies are in place for confirmed cases of HCWs in contact with patients?" ( $\mathrm{n}=24$ responded yes, $51 \%$ ) and "Is there a triaging system that can be applied to ARI [Acute Respiratory Infections, upper- or lower- respiratory tract infections which include the common cold, pneumonia and influenza] in the health facilities" ( $n=26$ responded yes, 54\%). Countries were more prepared for environmental controls ( $\mathrm{n}=48$ countries, $77 \%$ responded yes to $\mathrm{n}=1$ question) and PPE measures ( $n=44$ to $n=48$ countries, $67 \%$ responded yes to $n=2$ questions) [15].

In examining readiness for COVID-19 spread, we now review the outbreak in South Africa, currently the largest on the continent $[1,2]$. South Africa responded "yes" to all readiness questions except one administrative control question: "is there a triaging system that can be applied to ARI in the health facilities?" Even in a country like South Africa which is relatively well-prepared for COVID-19, we must examine any additional resources which can be leveraged for an even more effective response. As the country rapidly prepares for mitigating community spread through actions like a nationwide lockdown and travel restrictions, ensuring a coordinated infection prevention and control response at the facility-level can further improve these gains and can ensure that South Africa leverages all possible resources [16,17].

\section{SUPPORTING EXISTING SYSTEMS IN SOUTH AFRICA FOR A COORDINATED PANDEMIC RESPONSE}

South Africa is uniquely positioned to respond swiftly and broadly to emerging community transmission of COVID-19. With the largest HIV burden in the world and a high TB and MDR-TB burden, IPC practices are well understood and buy-in from providers, health officials and other stakeholders is high. To most effectively prepare for COVID-19 spread in hospital facilities, however, South Africa must look at current innovations within the national TB control program and those of TB technical assistance partners.

According to the most recent WHO Global TB report, South Africa is one of eight countries accounting for two thirds of the global TB burden ( $3 \%$ alone) and is listed as one of the 30 high TB burden countries 
[18]. TB is the leading infectious cause of death globally, killing over one million people in 2018 alone [18]. The disease is caused by Mycobacterium tuberculosis, which spreads when someone with TB expels the bacteria into the air, most commonly through coughing. The national TB control program in South Africa, along with key technical assistance partners like the USAID Tuberculosis South Africa Project, continue to develop and implement innovative TB IPC policies and interventions. One of these interventions is an administrative control measure meant to improve triage practices for patients with suspected TB while reducing time from hospital presentation to TB testing, from testing to diagnosis and from diagnosis to treatment initiation. This strategy, known as Finding cases Actively, Separating safely and Treating effectively (FAST), is currently implemented in $84 \%(n=86)$ of hospitals in eleven priority districts in South Africa, including OR Tambo, Sarah Baartman, Nelson Mandela Health Metro, Waterberg, Sekhukhune, Mangaung, Fezile Dabi, Johannesburg Health Metro, Tshwane Health Metro, eThekwini and uMkhanyakude [19].

Finding cases actively: The first pillar of the FAST strategy is to identify patients with suspected TB upon entry to a supported hospital. Upon entering a facility, a health care worker greets each patient and identifies those with TB symptoms, including those with an active cough, into an area separate from the general waiting area for patients. This process is conducted regardless of hospital ward and is not restricted to TB clinics in order to find as many patients with TB symptoms as possible, even those who may be at the hospital for an unrelated reason.

Separating safely: After identifying symptomatic patients, these patients are separated into a waiting area which is separate from the general waiting area, are given a surgical mask and are educated on cough hygiene. Patients are then asked to produce a sputum sample which is used for molecular testing (generally GeneXpert MTB/RIF assay) for identification of TB and resistance to rifampicin, a common first-line TB treatment. After the sample is given to laboratory technicians, a nurse will further separate patients into a separate waiting area. Laboratory technicians then test the sample immediately, and results are available on the same day, sometimes in as little as four hours (in which the sample result is available in two hours, and the result is delivered within four hours after performing internal quality checks and reporting) [20].

Treating effectively: If a sputum sample indicates presence of active $\mathrm{TB}$, a nurse will then explain the test result to the patient and begin anti-TB treatment. If rifampicin resistance is indicated, further drug susceptibility testing (DST) including line probe assay (LPA) and other testing may be indicated. Patients are generally started on treatment on the same day before leaving the facility and are referred to a lower-level health center for local, decentralized follow up care.

The FAST approach has identified 12636 additional TB cases which would have otherwise been missed. Additionally, the Tuberculosis South Africa Project has achieved high screening, testing and treatment initiation rates among patients entering supported facilities as shown in Table 2. Additional facilities have

Table 2. USAID Tuberculosis South Africa Project FAST Results in supported districts, 2017-2019

\begin{tabular}{|c|c|c|c|c|c|c|c|c|c|}
\hline Year & Quarter & $\begin{array}{c}\text { Patients } \\
\text { SGREENED (II) }\end{array}$ & $\begin{array}{c}\text { Patients } \\
\text { SCREened ( } \% \text { of } \\
\text { HeadCount) }\end{array}$ & $\begin{array}{l}\text { Patients Tested } \\
\text { WITH GeneXPert } \\
\text { (II) }\end{array}$ & $\begin{array}{l}\text { PATIENTS TESTED } \\
\text { WITH GeNEXPERT } \\
\text { (\% OF PRESUMPTIVE) }\end{array}$ & $\begin{array}{c}\text { PatIENTS } \\
\text { DIAGNOSED WITH } \\
\text { DS-TB (N) }\end{array}$ & $\begin{array}{l}\text { Patients DI- } \\
\text { Agnosed WUTH } \\
\text { DR-TB (II) }\end{array}$ & $\begin{array}{l}\text { DS-TB TREATMENT } \\
\text { INITIATION (\% OF } \\
\text { DIAGNOSED) }\end{array}$ & $\begin{array}{l}\text { DR-TB TREATMENT } \\
\text { INITIATION ( } \% \text { OF } \\
\text { DIAGNOSED) }\end{array}$ \\
\hline \multirow[t]{3}{*}{2017} & Q2 & 46328 & $31.4 \%$ & 1940 & $31.0 \%$ & 238 & 45 & $85.3 \%$ & $37.8 \%$ \\
\hline & Q3 & 91649 & $37.7 \%$ & 4298 & $41.5 \%$ & 601 & 159 & $75.5 \%$ & $8.8 \%$ \\
\hline & Q4 & 154183 & $56.3 \%$ & 3355 & $67.0 \%$ & 642 & 392 & $39.9 \%$ & $3.3 \%$ \\
\hline \multirow[t]{4}{*}{2018} & Q1 & 171867 & $52.8 \%$ & 3092 & $61.3 \%$ & 576 & 455 & $22.6 \%$ & $2.9 \%$ \\
\hline & Q2 & 241496 & $64.3 \%$ & 6046 & $65.6 \%$ & 796 & 476 & $41.1 \%$ & $4.8 \%$ \\
\hline & Q3 & 436083 & $63.0 \%$ & 13138 & $71.8 \%$ & 1352 & 121 & $89.4 \%$ & $52.1 \%$ \\
\hline & Q4 & 438674 & $67.6 \%$ & 8383 & $63.2 \%$ & 1473 & 143 & $88.9 \%$ & $32.2 \%$ \\
\hline \multirow[t]{4}{*}{2019} & Q1 & 549300 & $69.8 \%$ & 12042 & $69.2 \%$ & 1457 & 71 & $92.5 \%$ & $87.3 \%$ \\
\hline & Q2 & 512345 & $71.9 \%$ & 10783 & $60.7 \%$ & 1180 & 54 & $90.7 \%$ & $88.9 \%$ \\
\hline & Q3 & 603022 & $61.9 \%$ & 11015 & $70.0 \%$ & 1452 & 54 & $87.1 \%$ & $70.4 \%$ \\
\hline & Q4 & 399464 & $66.3 \%$ & 6442 & $63.4 \%$ & 851 & 48 & $88.2 \%$ & $87.5 \%$ \\
\hline Total & & 3644411 & $63.0 \%$ & 80534 & $62.7 \%$ & 10618 & 2018 & $78.4 \%$ & $18.8 \%$ \\
\hline
\end{tabular}

DS-TB - drug-susceptible tuberculosis, DR-TB - drug-resistant tuberculosis 
adopted the FAST approach in an incremental fashion, and The Tuberculosis South Africa Project has improved the proportion of patients screened from 37.6\% in Q2 of 2017 to 64.8\% in Q4 of 2019. Over the same time, the project improved the proportion of patients tested with GeneXpert MTB/RIF (GXP) from $40.8 \%$ to $66.5 \%$. Finally, the project has maintained high treatment initiation rates of drug-sensitive TB (DS-TB) (90.2\% in Q4 of 2019) and has improved the proportion of patient started on rifampicin-resistant TB (RR-TB) from $37.8 \%$ in Q2 of 2017 to $84.8 \%$ in Q4 of 2019.

Aside from the FAST initiative, the Tuberculosis South Africa Project works extensively in governance and policy guidance, contact management, environmental controls and awareness building activities to reduce stigma surrounding TB and to encourage people to get tested and start TB treatment. Taken together, these TB-specific IPC interventions serve as useful entry points for COVID-19 IPC responses. Importantly, these TB interventions are functional, have political buy-in and funding, have trained staff and facility-level champions, and have proven results. Health officials must look to functioning programs like these to mount a wide-ranging, agile response to the public health emergency that is COVID-19.

\section{CONTINUING THE MOMENTUM: TOWARD A UNIVERSAL CULTURE OF INFECTION PREVENTION AND CONTROL}

While South Africa serves as one example, other countries will necessarily be affected by the COVID-19 pandemic. Other studies including ecological analyses should be implemented to understand possible country-level associations between TB and COVID-19 burden, especially among high TB burden countries. As the body of evidence grows, more specific recommendations can be made to more effectively prepare for future airborne infection threats.

COVID-19 represents an unprecedented challenge for infection prevention and control. As shown in settings like South Africa, however, there are successful and functional TB IPC programs in place which can be mobilized quickly and universally to prevent widespread hospital-based infections. In using these strategies, TB program managers and other stakeholders must harness this opportunity for a sustained focus on acute respiratory infections and airborne infection control programs. TB is the biggest infectious disease killer globally and, while COVID-19 is a global public health emergency, we must maintain this urgency and momentum for TB IPC after the threat has passed.

As the world comes together to tackle the COVID-19 pandemic, it is important to ensure that essential services and operations for dealing with long-standing health problems continue to protect the lives of people with TB and other diseases or health conditions. Health services, including national programs to combat TB, need to be actively engaged in ensuring an effective and rapid response to COVID-19 while ensuring that TB services are maintained [21].

In funding and bolstering these existing TB IPC strategies for COVID-19 responses, country governments can improve airborne IPC interventions in general, to improve TB case detection, to reduce nosocomial infections and to reduce TB deaths generally. While the initial benefit in expanding these programs lies in preventing wide community transmission of COVID-19, we must recognize the opportunity in maintaining this level of response against TB to continue to reduce new TB infections and deaths from TB.

\section{CONCLUSION}

As COVID-19 continues to spread globally, we must look to existing health system capacity for a rapid and robust response. As shown by WHO, IPC readiness on the African continent varies and shows only moderate preparedness for impending outbreaks, in which South Africa represents the ideal scenario. In high TB burden countries like South Africa, IPC interventions, especially like those implemented by the USAID Tuberculosis South Africa Project, offer a ready-made entry point to broad airborne IPC responses with trained providers, guidance documents and facility-level champions. These programs must be expanded and resourced to minimize nosocomial infection and death. In expanding these programs, however, we must keep the future in mind and realize the 2-fold benefit of IPC programs: the immediate benefit of preventing COVID-19 outbreaks, and the long-term benefit of reducing ARI death in general, including deaths form TB. In the wake of World TB Day and in the context of a rapidly moving pandemic, there is no better resource for high burden TB countries than national TB control programs. We must rapidly expand and resource these programs to evade unnecessary death and suffering due to COVID-19 and other ARIs. 
Acknowledgements: We would like to thank the staff of the USAID Tuberculosis South Africa Project and their dedication to ending TB in South Africa. Additionally, we thank our colleagues at the National Department of Health in South Africa for their leadership and guidance in ending TB.

Funding: This study is made possible by the support of the American People through the United States Agency for International Development (USAID). The contents of this study are the sole responsibility of University Research Co., LLC (URC) and do not necessarily reflect the views of USAID or the United States Government. This work was completed under the terms of USAID Contract Agreement Number: AID-OAA-I-14-00035; Order Number: AID-674-TO-16-00002. The USAID Tuberculosis South Africa Project is held by the prime recipient, University Research Company, LLC. and implemented by sub-recipients BEA Enterprises (Potomac, MD, USA), Brigham and Women's Hospital/Harvard/Partners in Health (BWH/PIH; Boston, MA, USA), Centre for Communications Impact (CCI) formerly JHHESA (Pretoria, South Africa), NEXT (Pretoria, South Africa), World Health Organization (WHO; Geneva, Switzerland), and University of Pretoria (Pretoria, South Africa).

Authorship contributions: AM, HA and NK collaborated on the overall structure of the viewpoint. AM and MM completed data analysis and summarized results. LM, CD and SA provided technical inputs and helped contextualize the viewpoint. All authors reviewed and approved the final version of the manuscript.

Competing interests: The authors completed the ICMJE Unified Competing Interest form (available upon request from the corresponding author), and declare no conflicts of interest.

1 Johns Hopkins Coronavirus Resource Center. Johns Hopkins Coronavirus Resource Center. Available: https://coronavirus.jhu.edu/. Accessed: 24 March 2020.

2 Novel Coronavirus. (2019-nCoV) situation reports. Available: https://www.who.int/emergencies/diseases/novel-coronavirus-2019/situation-reports. Accessed: 25 March 2020.

3 Liew MF, Siow WT, MacLaren G, See KC. Preparing for COVID-19: early experience from an intensive care unit in Singapore. Crit Care. 2020;24:83. Medline:32151274 doi:10.1186/s13054-020-2814-x

4 Wong JEL, Leo YS, Tan CC. COVID-19 in Singapore-Current Experience: Critical Global Issues That Require Attention and Action. Available: https://jamanetwork.com/journals/jama/fullarticle/2761890. Accessed: 2020 Mar 25.

5 Onder G, Rezza G, Brusaferro S. Case-Fatality Rate and Characteristics of Patients Dying in Relation to COVID-19 in Italy. JAMA. 2020. Online ahead of print. Medline:32203977 doi:10.1001/jama.2020.4683

6 Emanuel EJ, Persad G, Upshur R, Thome B, Parker M, Glickman A, et al. Fair allocation of scarce medical resources in the time of Covid-19. N Engl J Med. 2020;382:2049-55. Medline:32202722 doi:10.1056/NEJMsb2005114

7 Rational use of personal protective equipment for coronavirus disease 2019 (COVID-19). Geneva: World Health Organization; 2020.

8 Truog RD, Mitchell C, Daley GQ. The toughest triage — allocating ventilators in a pandemic. N Engl J Med. 2020;382:19735. Medline:32202721 doi:10.1056/NEJMp2005689

9 Considerations for quarantine of individuals in the context of containment for coronavirus disease (COVID-19. Available: https://www.who.int/publications-detail/considerations-for-quarantine-of-individuals-in-the-context-of-containment-for-coronavirus-disease-(covid-19). Accessed: 13 March 2020.

10 Parmet WE, Sinha MS. Covid-19 — The law and limits of quarantine. N Engl J Med. 2020;382:e28. Medline:32187460 doi:10.1056/NEJMp2004211

11 Infection prevention and control during health care when novel coronavirus (nCoV) infection is suspected. Available: https://www.who.int/publications-detail/infection-prevention-and-control-during-health-care-when-novel-coronavirus-(ncov)-infection-is-suspected-20200125. Accessed: 25 March 2020.

12 Gates B. Responding to Covid-19 _ A Once-in-a-Century Pandemic? N Engl J Med. 2020;382:1677-9. Medline:32109012 doi:10.1056/NEJMp2003762

13 World Health Organization. Minimum requirements for infection prevention and control. Geneva: World Health Organization; 2019.

14 WHO African Region COVID-19 Readiness Response Sheets: Infection Prevention and Control. Geneva: World Health Organization; 2020. Available: https://app.powerbi.com/view?r=eyJrIjoiNWY4NTQyNWMtZjllYSOOMjAOLTgOMjYtMjRkNGE0ZmZiYmI5IiwidCI6ImY2MTBjMGI3LWJkMjQtNGIzOS04MTBiLTNkYzI4MGFmYjU5MCIsImMiOjh9. Accessed: 24 March 2020.

15 Jamison DT, Breman JG, Measham AR, Alleyne G, Claeson M, Evans DB, et al, editors. Disease Control Priorities in Developing Countries 2nd ed. Washington (DC): World Bank; 2006.

16 President Cyril Ramaphosa. Escalation of measures to combat Coronavirus COVID-19 pandemic I South African Government. Available: https://www.gov.za/speeches/president-cyril-ramaphosa-escalation-measures-combat-coronavirus-covid-19-pandemic-23-mar. Accessed: 25 March 2020.

17 Department of Home Affairs - Corona Virus Information]. Available: http://www.dha.gov.za/index.php/corona-virus-information. Accessed: 14 March 2020.

18 Global tuberculosis report 2019. Geneva: World Health Organization; 2019. Available: http://www.who.int/tb/publications/global_report/en/. Accessed: 14 March 2020. 
19 South Africa: University Research Co./USAID diagnose over 3 thousand patients with TB using facility-based screening strategy. Available: https://stoptb-strategicinitiative.org/index.php/2019/11/20/south-africa-university-research-co-usaid-diagnose-over-3-thousand-patients-with-tb-using-facility-based-screening-strategy/. Accessed: 14 Mar 2020.

20 Cepheid I MTB/RIF Molecular Test - Xpert MTB/RIF. Available: https://www.cepheid.com/en_US/tests/Critical-Infectious-Diseases/Xpert-MTB-RIF. Accessed: 25 March 2020.

21 World Health Organization. WHO Information Note: Ensuring continuity of TB services during the COVID-19 pandemic. Available: https://www.who.int/news-room/detail/12-05-2020-updated-who-information-note-ensuring-continuity-of-tb-services-during-the-covid-19-pandemic. Accessed:07 July 2020.

\section{Correspondence to:}

Alexander Moran, MSPH

5404 Wisconsin Ave. Suite 800

Chevy Chase, MD, 20815

USA

amoran@urc-chs.com 